\title{
EDITORIAL
}

\section{Will all ARDS patients be receiving mechanical ventilation in 2035? Yes}

\author{
Ignacio Martin-Loeches ${ }^{1,2,5^{*}}$ (D) Lieuwe D. Bos ${ }^{3}$ and Ewan C. Goligher ${ }^{4}$
}

C 2016 Springer-Verlag Berlin Heidelberg and ESICM

Intensive care has historically been synonymous with the provision of mechanical ventilation (MV). While extracorporeal techniques for supporting lung function (extracorporeal life support, ECLS) are attracting increasing interest, we hold that MV will remain the mainstay of care for patients with acute respiratory distress syndrome (ARDS) in 2035. Whilst ECLS technology will improve, some complications are likely to remain unavoidable even in 2035 (cannula-related complications including hemorrhage or infection, and neurological complications including hemorrhage, infarction, etc.). We argue that continued improvements in the delivery of ventilatory support would ensure that MV remains safer and more feasible than ECLS. Furthermore, we argue that MV is required to avoid injury from spontaneous breathing in ARDS.

Ongoing advances in the understanding of the pathophysiology of ventilator-induced lung injury will enable intensivists to effectively avoid the risks of ventilation in ARDS including ventilator-induced lung injury, ventilator-associated pneumonia, patient-ventilator dyssynchrony, and the need for sedation and analgesia. As a result, we expect that patients will recover more quickly leading to a much shorter duration of ventilation in 2035. Continued advances in non-invasive ventilation are likely to further mitigate these risks. Non-invasive mechanical ventilation and high flow nasal cannula may decrease the number of patients that require invasive MV. For example, a recently introduced form of respiratory support, high flow nasal cannula, improves outcomes in hypoxemic respiratory failure [1]. Furthermore, non-invasive

\footnotetext{
*Correspondence: drmartinloeches@gmail.com

1 Multidisciplinary Intensive Care, St. James's University Hospital, Dublin 8, Ireland

Full author information is available at the end of the article

For contrasting viewpoints, please go to

doi:10.1007/s00134-016-4456-7 and doi:10.1007/s00134-016-4487-0.
}

ventilation via a helmet interface was recently found to improve outcomes for patients with hypoxemic respiratory failure in a preliminary clinical trial [2]. Patientventilator dyssynchrony is associated with prolonged weaning and poor outcomes [3]; in 2035, closed loop MV will probably be very advanced and asynchronies could be reduced by machine learning systems and computerized close loop systems.

Safer mechanical ventilation (avoiding the adverse effects of MV) is also likely to prevent the development of ARDS, decreasing the need for consideration of ECLS. Recent observations suggest that MV can be injurious to the lung in patients without ARDS and that more widespread application of protective MV might prevent the development of ARDS. The implementation of an inspiratory pressure-limited approach has been associated with a lower progression to ARDS [4]. Moreover, a lower driving pressure has been associated with increase survival [5], although future prospective randomized controlled trials are necessary to test the hypothesis that the targeting of driving pressure is better than the current standard of care [6]. Recent meta-analyses suggest that MV with lower tidal volumes in patients without ARDS decreased the development of lung injury [7], even in the perioperative period [8].

The use of ECLS for ARDS apart from MV faces a critical challenge: the management of patient respiratory drive. Respiratory drive is dramatically elevated in the acute phase of ARDS via a range of pathophysiological mechanisms [9]. Large inspiratory muscle efforts resulting from high respiratory drive apply excessive and maldistributed stress and strain within the injured lung [10] and may also injure the respiratory muscles [11]. Indeed, abolition of respiratory muscle activity by neuromuscular blockade in ARDS has been shown to improve outcomes [12]. Whilst ECLS can modulate respiratory drive to some extent by clearing $\mathrm{CO}_{2}$ during the convalescent

\section{Springer}


phase of ARDS [13], the ability of ECLS to control respiratory drive in the acute phase of ARDS has not yet been demonstrated. ECLS cannot ameliorate respiratory drive arising from pulmonary mechanoreception or systemic (and brain stem) inflammation [14, 15]. Given the importance of controlling respiratory effort in the acute phase of ARDS to prevent lung injury, MV will continue to be required to enable sufficient administration of sedation and neuromuscular blockade to control respiratory effort and prevent lung injury. Therefore, MV will remain the best first option for the care of ARDS patients.

\section{Author details \\ ${ }^{1}$ Multidisciplinary Intensive Care, St. James's University Hospital, Dublin 8, Ireland. ${ }^{2}$ CIBERes, Madrid, Spain. ${ }^{3}$ Department of Intensive Care, Academic Medical Center, University of Amsterdam, Amsterdam, The Netherlands. ${ }^{4}$ Interdepartmental Division of Critical Care Medicine, University of Toronto, Toronto, Canada. ${ }^{5}$ Department of Clinical Medicine, Trinity College, Welcome Trust-HRB Clinical Research Facility, St James Hospital, Dublin, Ireland.}

\section{Compliance with ethical standards}

\section{Conflicts of interest}

On behalf of all authors, the corresponding author states that there is no conflict of interest.

Received: 25 June 2016 Accepted: 21 July 2016

Published online: 11 August 2016

\section{References}

1. Frat J-P, Thille AW, Mercat A et al (2015) High-flow oxygen through nasal cannula in acute hypoxemic respiratory failure. N Engl J Med 372:21852196. doi:10.1056/NEJMoa1503326

2. Patel BK, Wolfe KS, Pohlman AS et al (2016) Effect of non-invasive ventilation delivered by helmet vs face mask on the rate of endotracheal intubation in patients with acute respiratory distress syndrome: a randomized clinical trial. JAMA 315:2435-2441. doi:10.1001/jama.2016.6338
3. Blanch L, Villagra A, Sales B et al (2015) Asynchronies during mechanical ventilation are associated with mortality. Intensive Care Med 41:633-641. doi:10.1007/s00134-015-3692-6

4. Martin-Loeches I, de Haro C, Dellinger RP et al (2013) Effectiveness of an inspiratory pressure-limited approach to mechanical ventilation in septic patients. Eur Respir J 41:157-164. doi:10.1183/09031936.00221611

5. Amato MBP, Meade MO, Slutsky AS et al (2015) Driving pressure and survival in the acute respiratory distress syndrome. N Engl J Med 372:747755. doi:10.1056/NEJMsa1410639

6. Bellani G, Laffey JG, Pham T et al (2016) Epidemiology, patterns of care, and mortality for patients with acute respiratory distress syndrome in intensive care units in 50 countries. JAMA 315:788-800. doi:10.1001/ jama.2016.0291

7. Serpa Neto A, Cardoso SO, Manetta JA et al (2012) Association between use of lung-protective ventilation with lower tidal volumes and clinical outcomes among patients without acute respiratory distress syndrome: a meta-analysis. JAMA 308:1651-1659. doi:10.1001/jama.2012.13730

8. Sutherasan $Y$, Vargas M, Pelosi P (2014) Protective mechanical ventilation in the non-injured lung: review and meta-analysis. Crit Care 18:211. doi:10.1186/cc13778

9. Jacono FJ (2013) Control of ventilation in COPD and lung injury. Respir Physiol Neurobiol 189:371-376. doi:10.1016/j.resp.2013.07.010

10. Yoshida T, Torsani V, Gomes $S$ et al (2013) Spontaneous effort causes occult pendelluft during mechanical ventilation. Am J Respir Crit Care Med 188:1420-1427. doi:10.1164/rccm.201303-05390C

11. Orozco-Levi M, Lloreta J, Minguella J et al (2001) Injury of the human diaphragm associated with exertion and chronic obstructive pulmonary disease. Am J Respir Crit Care Med 164:1734-1739. doi:10.1164/ ajrccm.164.9.2011150

12. Papazian L, Forel J-M, Gacouin A et al (2010) Neuromuscular blockers in early acute respiratory distress syndrome. N Engl J Med 363:1107-1116. doi:10.1056/NEJMoa1005372

13. Bein T, Weber-Carstens S, Goldmann A et al (2013) Lower tidal volume strategy $\left(\approx 3 \mathrm{ml} / \mathrm{kg}\right.$ ) combined with extracorporeal $\mathrm{CO}_{2}$ removal versus "conventional" protective ventilation $(6 \mathrm{ml} / \mathrm{kg})$ in severe ARDS. Intensive Care Med 39:847-856. doi:10.1007/s00134-012-2787-6

14. Karagiannidis C, Lubnow M, Philipp A et al (2010) Autoregulation of ventilation with neurally adjusted ventilatory assist on extracorporeal lung support. Intensive Care Med 36:2038-2044. doi:10.1007/ s00134-010-1982-6

15. Jacono FJ, Mayer CA, Hsieh Y-H et al (2011) Lung and brainstem cytokine levels are associated with breathing pattern changes in a rodent model of acute lung injury. Respir Physiol Neurobiol 178:429-438. doi:10.1016/j. resp.2011.04.022 